can quite believe that in an asylum containing only 100 or 200 patients it might often happen that for many years at a time no case would require to be forcibly fed; but in our largest lunatic asylums, which contain from 1000 to 2200 patients in each, it rarely happens that many weeks pass without some patient requiring this treatment. Asylum medical officers can have no reason for performing this operation with unnecessary frequency, as it is by no means a pleasant duty, and brings neither pecuniary gain nor

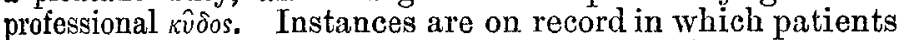
have been thus fed daily for many months, and even years; but it is my belief that when a patient has acquired an undesirable taste for being fed in this way, his troublesome habit may almost always be successfully combated by the exercise of a little tact ou the part of the medical attendant. I have no experience of any case in which the necessity for forcible feeding has existed for longer than three or four weeks at a time.

It is no part of my object in this letter to describe the best methods of forcible feeding, but merely to affirm that the operation is sometimes an absolute necessity for the saving of life, and that the lives saved are in a considerable proportion of cases those of patients who ultimately recover and return to their homes. If there are abuses in asylums (and what human institutions are perfect?), by all means let us hare them exposed and remedied; but at the present time, when the public mind is, causelessly, as I believe, somewhat uneasy upon the subject of the care and treatment of the insane, it is most undesirable that the idea should become general that insane persons are needlessly subjected to the discomfort of having tubes passed into their stomachs, even though the object be to supply them with the food necessary to their sustenance and recovery.

I am, Sir, your obedient servant, CHAS. S. W. COBBOLd, M.D.,

Sept. 23rd, 1892. Medical Superintendent, Earlswood Asylum.

\section{"A SIMPLE OPERATION FOR VARICOCELE."} To the Editor of THE LAXCET.

SIR, - In to-day's number of THE LANCET Mr. A. Barker reports three cases of varicocele under the above heading. It may perhaps be of interest to him and others who intend to try this method to know that I have also had a case in which I performed the operation in the same way as Mr. Barker, and with an equally good result. The case was a man aged fifty years, a miner, who was admitted under my care into the York County Hospital in April last, suffering from a laroe varicocele on the left side. I performed the operation in almost identically the same way as Mr. Barker, encircling the veins with a piece of Chinese silk (which had previously been boiled for half an hour in a ten per cent. solution, and afterwards left to soak for some hours in a twenty per cent. solution of carbolic acid); after tying, the ends of the silk were cut short, and dropped into the wound, which was closed up over them. The wound healed in a few days with scarcely any suppuration. I kept the man in the hospital for a fortnight after everything seemed quite well, and when he went out there was no sign of inflammation at all about the wound, which was soundly healed, and all that could be detected was a small nodule on the seat of ligature. I am, sir, yours faithfully,

York, Sept. 30th, 1882. W. H. JALLAND, F.R.C.S.

\section{THE QUEEN'S UNIVERSITY DEGREES.}

\section{To the Editor of THE LANCET.}

SIR, - Your correspondent "J. W. M." takes exception in last week's LANCET, to a statement made by me before the Royal Commission on the Medical Acts to the effect that "A student attending a Queen's College may obtain all the lectures necessary for a Queen's University Degree (or Scotch double diploma), in two years," which, he says, "is not a fact." That the statement is accurately true may be proved by anyone who pleases to examine the regulations of the Queen's University, published in your Student's number for 1881 and previous years. Two courses of lectures, at most, were required by the University in any subject, and these were readily obtained in two years. Indeed, I have known many students who-having put in, in a Queen's College, the essential two courses of medical, and two courses of non-medical lectures, all in one Winter Sessionhave taken all the remainder of their curriculum in Dablin, and have possessed their M.D. Q.U.I., and L.R.C.S. and C.P. Edin., long before the lapse of the statutory four years. It is true that the Q.U.I. required twenty-four months' hos pital, so that a student commencing in November of any year could not theoretically complete his hospital curriculum until two years and three months had elapsed, but that difficulty was always easily adjusted with the hospital authorities. Therefore, it is quite true, as I stated, that a student could (and many did) complete his entire curriculum for the M.D. Q.U.I. and Scoteh Double Diploma in a couple of months over two years, and that a great number of Irish students, therefore, took these qualifications in preference to the M.B. Dublin University, or L.R.C.S.I. or L.K.Q.C.P.I., which would have cost them an additional year's work and fees.

I am, Sir, yours, \&c. ARCHIBALD H. JACOB, M.D. Dub., F.R.C.S.I Dublin, Oct. 4th, 1882.

\section{DISTRIBUTION OF THE REPORTS OF THE LOCAL GOVERNMENT BOARD. \\ To the Editor of THE LANCET.}

SrR, - I have this day forwarded to the President of the Local Government Board a memorial from the North-Western and Yorkshire Associations of Medical Officers of Health, of which the enclosed is a copy.

I am, Sir, yours truly,

Manchester, Oct. 4th, 1882.

FRANCIS VACHER.

To the Right Hon. J. G. Dodson, M.P., President of the Local Government Boord.

The memorial of the North-Western and Yorkshire Associations of Medical Officers of Health.

Respectfully showeth, - That your memorialists are a body of Medical Officers of Health practising in the counties of Lancaster, Chester, Derby, and York. That your memorialists having been from time to time instructed and informed by the annual reports of the medical officer of your Honourable Board, and forming a high estimate of the importance of the topics discussed in the said reports, and having experienced difficulty in obtaining copies of the same owing to the small number printed, humbly pray that your Honourable Board will order that a copy of the said report, with appendices, may henceforth annually, as issued, be presented to every medical officer of health whose appointment shall have the sanction of your Honourable Board. And your memorialists will ever pray, \&c.

(Signed on behalf of the North-Western Association of Medical Officers of Health.

WM. Hugh Hughes, President.

Francrs Vacher, Hon. Sec.

(Signed on behalf of the Yorkshire Association of Medical Officers of Health.)

S. W. North, President.

J. M ITCHeLl Wilson, M.B., Hon. Sec.

100, King-street, Manchester, Oct. 4th, 1882.

\section{NEW CA S T L E - O N - T Y N E. (From our oun Correspondent.)}

AT the sanitary meetings on Thursday, the $28 \mathrm{th}$ ult., the following were read and discussed :-Address by Professor Robinson. C.E., Vice-president of the Section, in which he strongly pointed out the necessity of proper training for inspectors. W. Eassie, C. E. : "The Desirability or otherwise of providing Town and Country Houses with Grease Intercepting Chambers in Scallery Sinks." J. Lemon, M. I.C.E. : "The Separate System of Drainage." E. C. Robins, M.I.C.E. : "On the Original Experiments of Dr. Renk of Munich, with Sewer Gas, and the Mode of its Exclusion from Dwelling Houses." W. G. Laws : "Sewer Ventila. tion." John Price: "Industrial Dwellings." W. Eassie, C.E. : "On the Sanitary Needs of Town and Country 